\title{
Integration of Science, Education and Industry in the Republic of Kazakhstan in the Context of the Development of New Educational Programs
}

\author{
Ualikhan Abdibekov \\ Al-Farabi Kazakh National University, Almaty, Kazakhstan \\ Email: uali1@mail.ru \\ Dauren Zhakebayev \\ Al-Farabi Kazakh National University, Almaty, Kazakhstan \\ Email: Dauren.Zhakebaev@kaznu.kz \\ Oksana Karuna \\ Al-Farabi Kazakh National University, Almaty, Kazakhstan \\ Email: Oksana.Karuna@kaznu.kz \\ Yekaterina Moisseyeva \\ Al-Farabi Kazakh National University, Almaty, Kazakhstan \\ Email:k.moisseyeva@gmail.com
}

Doi:10.5901/mjss.2015.v6n6s5p364

\begin{abstract}
After gaining the independence, the sovereign Kazakhstan has started to actively reform the education sector. Significantly expanding the international cooperation, Kazakhstan gratefully accepted assistance from the European Union and became one of the main participants of many projects aimed at the globalization of education (TEMPUS, ERASMUS MUNDUS, Erasmus +, etc.). After the twenty years of the reforms, the Republic of Kazakhstan has achieved the significant results. Retaining the education fundamentality constructed in the Soviet era, the multinational Asian country has adapted the old education system to the European standards. This is evidenced by the fact that more than $70 \%$ of the specialties of the leading universities of Kazakhstan have received an accreditation certificate from the European Union. In the paper, the aspects of the phased formation of a "new" education in the Republic of Kazakhstan are considered. Also, the issue of the integration of the education and the science in the industry is highlighted and the recommendations for the quality implementation of the integration process within the framework of higher and postgraduate education are given.
\end{abstract}

\section{Introduction}

Unfortunately, the review of the Kazakhstan activity is poorly represented in the arena of the world publications. There are only individual researches on the demographic situation in the Republic of Kazakhstan ("Kazakstan 1995", 1997) and on the protection of health (Martin, 1979), and the ethnonational studies of the countries of the former Soviet Union (Brubaker, 2011). Also, there are some articles on the education in Russia (Bittar and Ferreira, 2015; Kozar, 2015; Harris, Jones, Adams, Perera and Sharma, 2014), mentioning Kazakhstan. Sufficiently detailed information about the formation of Kazakhstan as an independent country is reflected in the book ("Kazakstan. Transition", 1997).

It is necessary to emphasize the Kazakhstan colleagues' works covering the information on the modernization of the higher education in the country. For example, Maudarbekova and Kashkinbayeva (2014) highly detailed considered the issue of the international programs and projects which are implemented in the Republic of Kazakhstan. The importance and the necessity of the entry into the world educational environment were emphasized. Additionally, some recommendations to improve the educational process in Kazakhstan were given.

Aikenova (2014) in her work describes the history of the formation of the new phases of the education in the 
Republic of Kazakhstan. The processes of globalization caused Kazakhstan become a partner of a Bologna process in 2010 in order to join the European education space. As a result, the old education system and educational policy in Kazakhstan met new changes: academic mobility of tutors and students, three-level education at universities.

There are articles covering the distance and e-learning education (Kenzhebayev and Dalayeva, 2014; Turumbetova, 2013). Also, some authors analyze the influence of the religion on the education in Kazakhstan (Erpay and Jandarbek, 2014).

In the works by Egamberdiyev (2014), the basic problems faced by Kazakhstan carrying out large scale educational reforms were studied. The result of modernization and the forecast were clearly formulated as well as the weak points of the new higher education were marked.

However, currently there is no data on how the programs of the integration of the science and the education in the industry are implemented. This article focuses on this aspect precisely.

\section{Prerequisites}

The necessity of the close cooperation between the education, the science and the industry is determined by the importance of the knowledge-based economy development. This is especially relevant for the contemporary world, where equipment and technology are updated every day.

To date, the Head of the State Nursultan Nazarbayev (2013) very clearly defines the educational strategy for the country, in which a close partnership of the three components of the economic growth (education, science and industry) is required.

At present, in the Republic of Kazakhstan the great attention is paid to the innovative development, and in the conditions of the current global economic situation the factors constraining acceleration of the innovative and technological breakthroughs are primarily being identified. The necessary condition to the implementation of such a policy is the effective use of the intellectual property, especially scientific discoveries and inventions, to enhance the competitiveness and the effective economic development. The leading role in this process belongs to the educational system which must meet the demands of the market and production.

At this point, in the conditions of global economic instability, the necessity to exploit the potential of the production sector has arisen with a view to determine the intensive growth of the manufacturing sector by the education and the science. The implementation of such a process is not an easy task for universities, because the educational institution can use the manufacturing sector only in agreement of the necessary competencies which a graduate of the higher school must have in order to perform high-technology and science-intensive production tasks. The construction of the innovative educational system is the main task of the human capital formation. Such a system should ensure the generation of qualified professionals which are very susceptible to innovation, ready to create and implement the innovative projects, to implement the new ideas in the technological processes, and to easily carry out approbation of the new developments.

\section{Development of Educational Programs}

Speaking about the creation of a strong partnership of the science, the education and the industry, it is necessary, first of all, to consider the process of the developing the educational programs. Al-Farabi Kazakh National University, as the flagship of the Republic of Kazakhstan, has already started the process of the educational programs modernization in the framework of the integration of universities and research institutes. Since 2014, the KazNU has being implemented the new educational programs to the educational process for the master and PhD students. These programs contain the specially developed disciplines for teaching which the researchers and scientists have being attracted from the scientific research institutes. The present programs have been successfully implemented and come to fruition. The master and $\mathrm{PhD}$ students get acquainted with the recent research and developments on the spot and get the knowledge directly from the authors. It could be said that the process of the integration of the science and the education is successfully started. It should continue this trend and to develop the educational programs that would bring together science, industry and education.

It is necessary to conduct the continuation of the process of the establishing the close partnership of the science, the education and the industry, by the change of the educational programs for all levels of the education. It is proposed to change the goals and objectives of the industrial practice for bachelor, master and $\mathrm{PhD}$ students without violating the integrity and the fundamental orientation of the educational programs. For example, the formulation of the theme of the final bachelor and master theses for $50 \%$ of students should be done with the participation of the representatives from the 
manufacturing sector. World experience shows that only one expert of 10 students who have successfully passed industrial practice is really required in the production. In Kazakhstan, the shortage of epy qualified personnel is still there, but the employer is not willing to provide all students undergoing practical training with jobs. The special attention should be paid to this problem while developing the educational programs. It is necessary to provide the student with the fundamental knowledge that will give the student the opportunity of the employment in the different spheres of the production.

The view that it is necessary to involve the experts from the production to teaching in the universities, is often expressed. However, this can not be done ever, because this "teacher", as a technologist, will not be able to give the fundamental knowledge on which skills to work with technological tasks base. Undoubtedly, this specialist can give a very valuable knowledge on the process of the production of something or the technology of the process. But in the era when every day the technologies are changed, the information, the technical resources and the software are updated, and the general direction of the economy also can be changed, only the fundamental knowledge may be in the high value. Just the fundamental knowledge will allow the graduate in the case of the loss of the relevance of one production type to become specialist in another sector. Of course, the university should prepare specialists, focusing on the needs of the Kazakhstan market. However, this does not mean that the education and the science should be focused only on the tasks demanded in Kazakhstan. Under globalization, the world economic landmarks should be determined, the focus should be on the knowledge-based industries and the IT sector, and the economy development should march in unison with the advanced technologies, and it is all should be done without giving importance to the possibility of only one state. It should also pay particular attention to that the student should be able not only to develop something new and useful to the global economy, but also should be able to declare copyright and to obtain protective document. In this case, our country will begin receiving more recognition abroad.

At the same time, it is almost impossible for the university to work directly with the production sector, as it is quite difficult for the scientist to identify the range of the production problems that need to be immediately solved. The available experience of the scientific research institutes and the research centers on the definition of the class of the relevant to the country's economy trends of the development can help to attract the employees of the university to the realization of the manufacturing sector problems.

The scientific research institutes always have the close relationship with the industry, and the educational institutions are willing to cooperate with the research institutes. The work of the university through the scientific research institutions with the industrial enterprises and the large holdings will help to organize activities on the establishment of the strategic plans of the production development, to prepare the highly specialized staff at the national level, to increase the scale of the applied research, and to guide the development of the republic's economy.

This process is illustrated in fig. 1 which shows that the university does not have to directly carry out the work with the production organization, because this function should be performed by the scientific research centers. In the words of the Head of the State Nursultan Nazarbayev (2013), it is necessary to create independent centers of proficiency testing so that we produce the professionals which are in demand for the production. The aim of these centers will be to define the range of the problems which solution requires the scientific support and the involvement of the university employees and students to work on such projects. This connection, firstly, will save the important fundamental component of the education, and, secondly, will help to create the favorable environment for the integration of the science and the education in the industry.

It is necessary to implement already now the development of the proposed partnership of the science, the education and the industry under the State program of the industrial-innovative development of the Republic of Kazakhstan for 2015 - 2019 years.

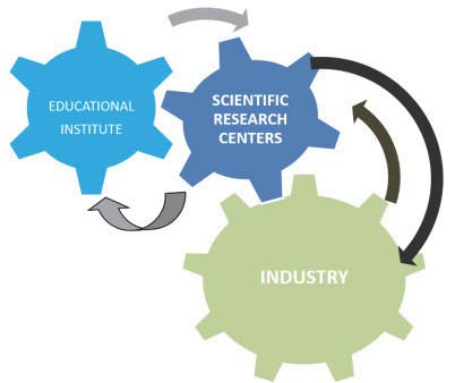

Fig. 1. The connection of the science, the education and the industry 


\section{Information and Communication Technologies}

Let us illustrate the relevance of the development of such programs by the example of the application of the educational technology in the field of the information and communication technologies (ICT). The development of information and communication technologies is one of the most important factors in improving the competitiveness of the Kazakhstan economy.

Modern information and communication technologies have completely changed the habitual way of the life of all mankind. The new markets and business models to support the input, storage, processing, analysis and presentation of information have appeared, and this process continues to evolve and expand at a rapid pace. The traditional economy based on the industry is now being transformed into the knowledge-based economy. The information technology began to be seen as a means to provide the improvements in the socio-economic conditions and as the tools to achieve the global goals.

The inherent for the sector speed of the development is a problematic point for the development of other sectors based on ICT. Today in Kazakhstan at the state level the great research and practical work on the implementation and development of ICT is realizing. Such transformations affect all sectors of the economy, including the education. For the development and implementation of ICT, the need for highly qualified personnel appears. Nowadays it is one of the main issues that need to be solved. The sector of the information resources is highly dynamically developing, and requires the constant improvement of the professional skills. Therefore it is important to continuously ensure the advanced training of the personnel and training the specialists on the demanded professions in the higher and special secondary educational institutions.

Creating favorable conditions for the scientific research activities and the implementation of measures and tools for the commercialization of innovative ICT ideas is an important step in the achieving the results of the development of the ICT sector. All this indicates that the time has come for the training of the new format personnel: professionals who are able to create new technologies, based on the fundamental knowledge, to promote new ideas, thus developing IT sector of our country. The training specialists of such a profile is only possible on the basis of the master educational programs focused on obtaining both fundamental knowledge and knowledge of the most advanced ICT, the use of the highperformance systems, the nanotechnology, the new materials, the advanced software, the latest programming technologies, and much more.

Despite the significant scale of taken in recent years measures to support the ICT sector and the implementation of the specific projects and programs of the industrial development of the Republic of Kazakhstan, the following problems remain as the main problems for the training the ICT specialists:

1. the lack of the incentives for the young people to develop and introduce the new technologies;;

2. the dependence of the Kazakhstan ICT market on the foreign one;

3. the low awareness of the students in the secondary and higher educational institutions of the Republic of Kazakhstan on the possibility of the developments in the field of ICT;

4. the low level of the susceptibility of the Kazakhstan business to the technological innovations;

5. the lack of the incentives for the transfert of the advanced technologies;

6. ineffectiveness of the mechanisms for the solution and searching the priority technological problems of the enterprises and businesses;

7. the lack of close connection between the education and the business;

8. the lack of technological and managerial competencies;

9. the underdevelopment of the innovative technologies in the educational system;

10. the imperfection of the control system for the implementation of the innovative projects.

\section{Acknowlegment}

The article was prepared within the project of the government assignment of the Ministry of education and science of the Republic of Kazakhstan «Development of mechanisms to improve quality of postgraduate programs under university autonomy and integration with scientific research institutions in accordance with international qualification standards»

\section{References}

Aikenova, D. (2014). Impact factors of education policy in Kazakhstan: SWOT-analysis. Procedia - Social and Behavioral Sciences, 152, 414-416 
Bittar, M., \& Ferreira JR., A. (2015). Pedagogical activism and principles of the school's work in the early days of soviet education. Revista Brasileira de Educação, 20(61), 433-456. doi: 10.1590/S1413-24782015206108

Brubaker, R. (2011). Nationalizing states revisited: projects and processes of nationalization in post-Soviet states. Ethnic And Racial Studies, 34(11), 1785-1814. doi: 10.1080/01419870.2011.579137

Egamberdiyev, M., \& Kozybakova, F. (2014). Integration of higher education in the Republic of Kazakhstan national innovation systems. Procedia - Social and Behavioral Sciences, 131, 224-228.

Erpay, I., \& Jandarbek, Z. (2014). A problem of religion study teaching in an independent Kazakhstan. Procedia - Social and Behavioral Sciences, 141, 352-356.

Harris, A., Jones, M.S., Adams, D, Perera, C.J., \& Sharma, S. (2014). High-performing education systems in asia: leadership art meets implementation science. Asia-Pacific Education Researcher, 23(4), 861-869. doi: 10.1007/s40299-014-0209-y

Kazakstan 1995: results from the demographic and health survey. (1997). Studies in Family Planning, 28 (3), $256-260$. doi: $10.2307 / 2137894$

Kazakstan. Transition of the state. (1997). World Bank: Country Study. ISBN: 0821339028

Kenzhebayev, G., \& Dalayeva, T. (2014). E-learning in the system of the pedagogical education in Kazakhstan. ERPA International Congress on Education, 6-8 June 2014, Istanbul, Turkey

Kozar, O. (2015). Discursive practices of private online tutoring websites in Russia. Discourse-Studies In The Cultural Politics Of Education, 36(3), 354-368, doi: 10.1080/01596306.2013.871238

Maudarbekova, B., \& Kashkinbayeva, Z. (2014). Internationalization of Higher Education in Kazakhstan. Procedia - Social and Behavioral Sciences, 116, 4092-4097.

Martin, J. (1979). Implementation of primary health-care. International Development Review, 21(2), 23-28.

Nazarbayev, N. (2013). Address by the President of the Republic of Kazakhstan, Leader of the Nation, N.Nazarbayev "Strategy Kazakhstan-2050": new political course of the established state" Retrieved from http://www.akorda.kz/en/page/page_address-bythe-president-of-the-republic-of-kazakhstan-leader-of-the-nation-n-nazarbayev-"strategy-kazakhstan-2050"-new-political-courseof-the-established-state"_1357813742

Turumbetova, L. (2014). Changes in the system of higher professional education in multiethnic Kazakhstan due to globalization. Procedia Social and Behavioral Sciences, 116, 4889-4893. 